\title{
Use of a Supportive Kidney Care Video Decision Aid in Older Patients: A Randomized Controlled Trial
}

\author{
Nwamaka D. Eneanya $a, b, c, d$ Shananssa G. Percy ${ }^{e}$ Taylor L. Stallings ${ }^{b}$ \\ Wei Wang $^{b}$ David J.R. Steele ${ }^{e}$ Michael J. Germain ${ }^{f}$ Jane O. Schellg \\ Michael K. Paasche-Orlow ${ }^{\text {h }}$ Angelo E. Volandes ${ }^{i}$
}

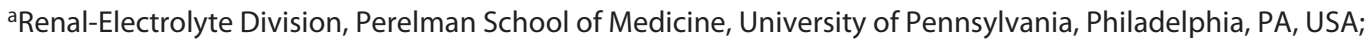
bPalliative and Advanced IIIness Research Center, Perelman School of Medicine, University of Pennsylvania, Philadelphia, PA, USA; 'Center for Clinical Epidemiology and Biostatistics, Perelman School of Medicine, University of Pennsylvania, Philadelphia, PA, USA; 'Leonard Davis Institute of Health Economics, University of Pennsylvania, Philadelphia, PA, USA; 'Division of Nephrology, Department of Internal Medicine, Massachusetts General Hospital, Harvard Medical School Center, Boston, MA, USA; fDivision of Nephrology, Baystate Medical Center, University

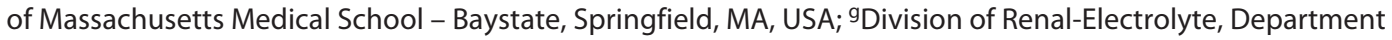
of General Medicine, Section of Palliative Care and Medical Ethics, University of Pittsburgh School of Medicine, Pittsburgh, PA, USA; hSection of General Internal Medicine, Boston Medical Center, Boston University School of Medicine, Boston, MA, USA; 'Division of General Medicine, Department of Internal Medicine, Massachusetts General Hospital, Harvard Medical School, Boston, MA, USA

\section{Keywords}

Chronic kidney disease - Dialysis decision-making .

Supportive kidney care · Palliative nephrology

\begin{abstract}
Background: There are few studies of patient-facing decision aids that include supportive kidney care as an option. We tested the efficacy of a video decision aid on knowledge of supportive kidney care among older patients with advanced CKD. Methods: Participants (age $\geq 65$ years with advanced $(K D$ ) were randomized to receive verbal or video education. Primary outcome was knowledge of supportive kidney care (score range $0-3$ ). Secondary outcomes included
\end{abstract}

karger@karger.com

(c) 2020 S. Karger AG, Basel

www.karger.com/ajn

Karger" preference for supportive kidney care, and satisfaction and acceptability of the video. Results: Among all participants ( $n=100)$, knowledge of supportive kidney care increased significantly after receiving education $(p<0.01)$; however, there was no difference between study arms $(p=0.68)$. There was no difference in preference for supportive kidney care between study arms $(p=0.49)$. In adjusted analyses, total health literacy score (aOR 1.08 [95\% Cl: 1.003-1.165]) and nephrologists' answer of "No" to the Surprise Question (aOR 4.87 [95\% Cl: 1.22-19.43]) were associated with preference for supportive kidney care. Most felt comfortable watching the video (96\%), felt the content was helpful (96\%), and would recommend the video to others (96\%). Conclusions: Among older patients with advanced CKD, we did not detect 
a significant difference between an educational verbal script and a video decision aid in improving knowledge of supportive kidney care or preferences. However, patients who received video education reported high satisfaction and acceptability ratings. Future research will determine the effectiveness of a supportive kidney care video decision aid on real-world patient outcomes. Trial Registration: NCT02698722 (ClinicalTrials.gov).

(c) 2020 S. Karger AG, Basel

\section{Introduction}

The proportion of older patients with CKD continues to increase in the USA. Indeed, in the past decade, the prevalence of CKD has grown from 9.2 to $14.5 \%$ among Medicare beneficiaries [1]. Furthermore, among those with more advanced disease in this population, nearly $20 \%$ will progress to ESRD within 5 years [2]. Treatment options for patients with ESRD include renal transplantation, hemodialysis, peritoneal dialysis, and, uncommonly, supportive kidney care. For older and frail patients for whom transplant is not an option, dialysis may not improve health-related quality of life or result in a significant increase in survival compared to those who receive medical management of kidney disease [3-6]. Supportive kidney care includes non-dialytic medical therapy focused on treatment of fluid balance, anemia, blood pressure, and nutrition, in addition to other physical and emotional symptoms [7]. As supportive kidney care allows people to maintain their quality of life and achieve quality end-of-life care, it is a reasonable treatment option for older and frail patients with advanced CKD [810].

Patients with advanced CKD and their caregivers desire patient-centered information regarding their ESRD treatment options but supportive kidney care is often not discussed [11-13]. Also, there is limited evidence about how best to inform patients about non-dialytic treatments and pre-dialysis education program processes vary widely [14-19]. Educational video decision aids have been studied in randomized controlled trials (RCT) to better promote informed decision-making among patients with kidney disease, dementia, heart failure, and cancer; however, none have included supportive kidney care [20-23]. Thus, we conducted an RCT to test preliminary efficacy of a video decision aid on supportive kidney care knowledge and preferences among older patients with advanced CKD.

\section{Methods}

\section{Trial Design}

We performed this prospective 2 parallel-arm RCT among patients with advanced CKD in Boston, MA, and Philadelphia, PA, USA. We calculated that 50 participants per arm would achieve $85 \%$ power to detect a $0.5 \mathrm{SD}$ of change in supportive kidney care knowledge after receiving education [24, 25]. Although the video featured older adults, study enrollment was initially open to include all adult patients ( $\geq 18$ years) to achieve enrollment targets more rapidly. However, the protocol was subsequently changed to limit enrollment to older participants in line with suitability of the educational content. Participants were randomized in a 1:1 fashion to receive either video or verbal education about hemodialysis, peritoneal dialysis, and supportive kidney care. One of the study investigators (N.D.E.) generated random numbers by computer and concealed these in envelopes. Study coordinators produced allocation results immediately before administering education. Participants were enrolled between July 2016 and March 2019. This study is registered at ClinicalTrials.gov (\#NCT02698722) and was approved by the Institutional Review Boards at Partners HealthCare and the University of Pennsylvania. Reporting was done in accordance with the CONSORT statement for RCTs [26].

\section{Settings and Participants}

Study participants were recruited from nephrology clinics associated with Massachusetts General Hospital and the University of Pennsylvania. Inclusion criteria identified in the patient's electronic medical record included: age $\geq 65$, advanced CKD (as defined by the Chronic Kidney Disease Epidemiology Collaboration [27] or Modification of Diet in Renal Disease Study Group [28] estimated glomerular filtration rate $<30$ ), and English-speaking. Patients were ineligible if they had a documented history of dementia, had a documented history of legal blindness, or were active on a kidney transplantation waitlist. For patients who met the inclusion criteria, primary nephrologists confirmed study eligibility and appropriateness with the study coordinators. The study coordinators then approached potential participants at the beginning or end of their clinic appointment. If interested in the study, the study coordinators obtained written informed consent. Enrolled participants who were deemed to have severe cognitive deficit (as determined by 8 or more errors on the Short Portable Mental Status Questionnaire [29]) were withdrawn from the study. All study procedures were conducted in a private room in the nephrology clinic.

\section{Video Education (Intervention)}

An 11.5-min video script was developed in an iterative process by a national panel of nephrologists with an expertise in shared decision-making in the CKD population. The video included images of older patients undergoing hemodialysis as well as patients doing peritoneal dialysis. For supportive kidney care, images of patients filmed in their home and clinic settings were used. The visual scenes were filmed without the use of prompts or stage directions to convey a candid realism in the style known as cinéma vérité $[30,31]$. All filming and editing were performed by a research team member (A.E.V.). All patients who were included in the video gave informed consent to be filmed, and no actors or special effects were used. 


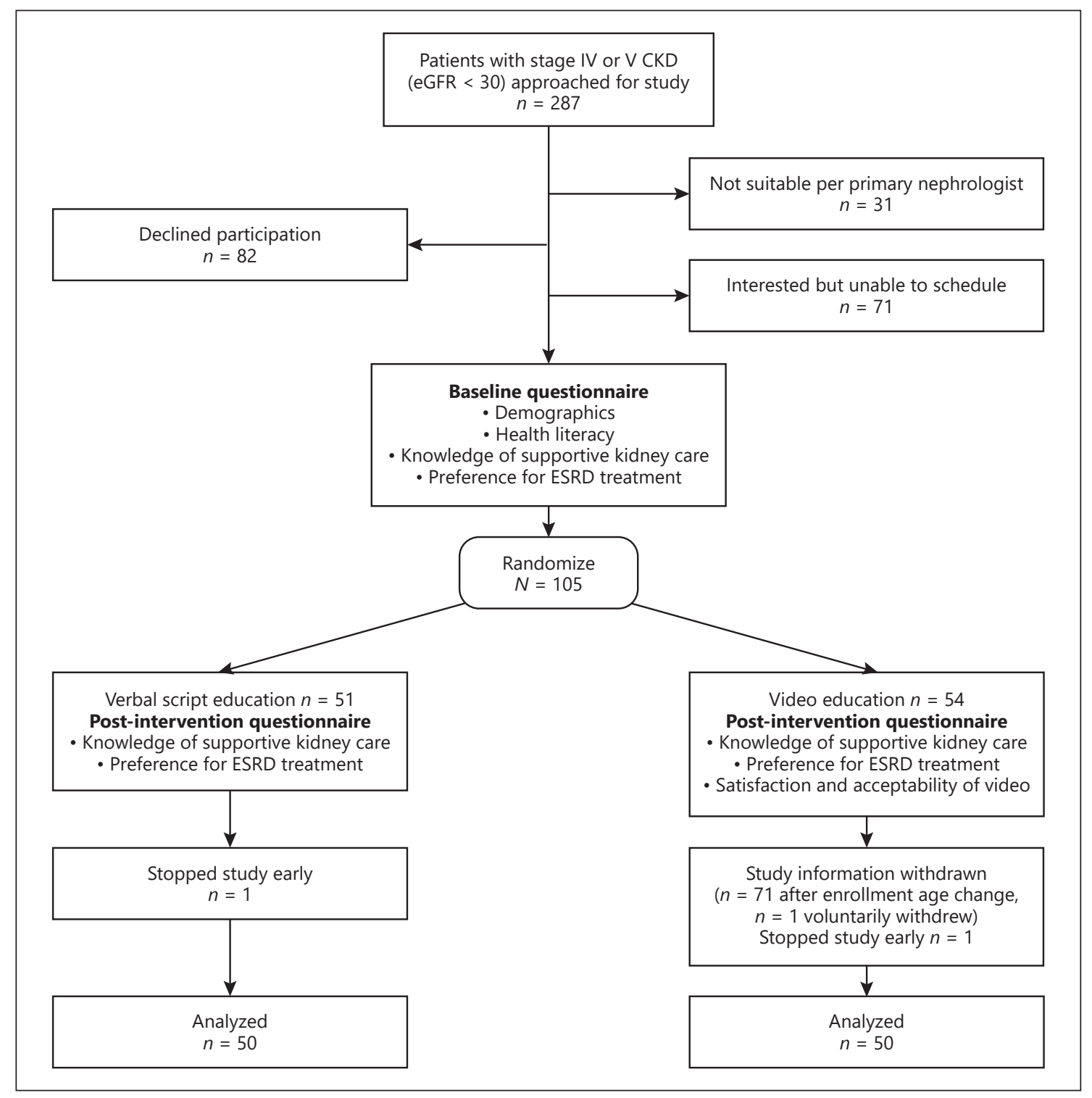

Fig. 1. Study schema.

\section{Verbal Education (Control)}

Similar to previously published RCTs of video decision aids, a short script was developed based on the script used for the video $[21,32]$. The language used in the script was written to target a low health literacy audience. Study coordinators read the script aloud to each participant.

\section{Outcome Measures}

The primary outcome was participants' knowledge of supportive kidney care. A 1-item survey was used to ascertain knowledge about supportive kidney care and featured 3 correct answers. Each correct response contributed 1 point. Incorrect or "I do not know" responses contributed no points. Knowledge scores ranged from 0 to 3 (see online suppl. Table 1; for all online suppl. material, see www.karger.com/doi/10.1159/000509711).
Secondary outcomes included participant preference for supportive kidney care if their kidney disease worsened to ESRD (one item) as well as satisfaction (one item) and acceptability (3 items) ratings for participants who received video education (see Supplement). Study coordinators administered all surveys pre-randomization and immediately post-education to each participant.

\section{Other Measures}

We ascertained participant demographic information (age, sex, race, ethnicity, education level, and income level) via interviewerassisted surveys. Health literacy was measured using the Rapid Estimate of Adult Literacy in Medicine (REALM), which has been used widely among patients with CKD and ESRD [33-36]. A score of $\leq 60$ is consistent with inadequate health literacy. We performed medical chart review to ascertain comorbidities to calculate a 
Table 1. Baseline characteristics

\begin{tabular}{|c|c|c|c|}
\hline Variable & $\begin{array}{l}\text { Total } \\
(N=100)\end{array}$ & $\begin{array}{l}\text { Verbal script } \\
(N=50)\end{array}$ & $\begin{array}{l}\text { Video } \\
(N=50)\end{array}$ \\
\hline Median age, years [interquartile range] & $75[70,81]$ & $75[70,81]$ & $76[70,81]$ \\
\hline Male gender, $n(\%)$ & $51(51)$ & $32(64)$ & $19(38)$ \\
\hline \multicolumn{4}{|l|}{ Race, $n(\%)$} \\
\hline White & $66(66)$ & $35(70)$ & $31(62)$ \\
\hline Black & $31(31)$ & $14(28)$ & $17(34)$ \\
\hline Asian & $1(1)$ & 0 & $1(2)$ \\
\hline Other & $2(2)$ & $1(2)$ & $1(2)$ \\
\hline Non-Hispanic ethnicity, $n$ (\%) & $97(97)$ & $49(98)$ & $48(96)$ \\
\hline Education, $n(\%)<$ high school & $15(15)$ & $4(8)$ & $11(22)$ \\
\hline Income, $n(\%)<30 \mathrm{k}$ & $38(38)$ & $16(32)$ & $22(44)$ \\
\hline Limited health literacy, $n(\%) \leq 60$ on REALM & $32(32)$ & $14(28)$ & $18(36)$ \\
\hline Median Charlson Comorbidity Index score [interquartile range] & $7[6,8]$ & $7[6,8]$ & $7[6,8]$ \\
\hline Nephrologist referred for pre-dialysis education, $n(\%)$ & $22(22)$ & $6(12)$ & $16(32)$ \\
\hline Surprise question, $n(\%)$ nephrologists that answered no & $23(23)$ & $9(18)$ & $14(28)$ \\
\hline
\end{tabular}

Charlson Comorbidity Index score for each participant [37]. Last, the participant's nephrologist was asked 2 questions: (1) "Have you referred your patient for pre-dialysis education?," and (2) "Would you be surprised if this patient died in the next 1 year?" (also known as the Surprise Question) [38]. We included these 2 items to better understand participants' views of supportive kidney care and to also identify those with limited prognoses who might benefit from this treatment.

\section{Statistical Analyses}

All analyses were performed using SAS version 9.4 (SAS Institute, Inc., Cary, NC, USA). All participant characteristics and outcomes were described using proportions for categorical variables and means $( \pm S D)$ or medians (interquartile range) for continuous variables depending on their distribution. Participant characteristics were summarized and then stratified by those who received verbal script education versus those who received video education.

Mean knowledge scores, the proportion of participants who achieved correct knowledge of all 3 supportive kidney care items (yes/no), and the proportion of participants who indicated preference for supportive kidney care (yes/no) were tabulated before and after receiving education. We compared overall post-intervention knowledge scores with pre-intervention knowledge scores using paired $t$ tests and binary outcomes between the study arms using Fisher's exact test. We used McNemar's statistic to summarize agreement, or the effect of education on the outcome, for each study arm. Multivariable logistic regression analyses were performed to identify independent association of participant characteristics (age, sex, race, ethnicity, income level, educational level, Charlson Comorbidity score, and health literacy), physician characteristics (referral pre-dialysis education, answer to the Surprise Question), and educational arm with correct knowledge and preference for supportive kidney care. Odds ratios with 95\% confidence intervals were calculated as the measure of association. Variables were checked for collinearity. Significance was determined at a 2-sided alpha level of 0.05 .

Randomized Clinical Trial

\section{Results}

\section{Baseline Characteristics}

Two hundred eighty-seven eligible patients were approached for study participation during their nephrology clinic visit (Fig. 1). Of these, 31 were not suitable for enrollment as determined by their primary nephrologist, 82 declined to participate, and 71 were interested but could not be enrolled due to the logistics of arranging and completing study procedures. Two participants consented but did not wish to complete the study. Three participants' study information were withdrawn (2 after study enrollment age changed to $\geq 65$ and 1 voluntarily). We continued to recruit to achieve our enrollment target and a total of 100 participants provided information for final study analyses.

The median age of all participants was 75 years (interquartile range: 70,81$)$ and the majority of participants were male $(51 \%)$, of White race $(66 \%)$, and of non-Hispanic ethnicity (97\%) (Table 1). Thirty-eight percent of patients had an annual income of less than 30,000 USD, $15 \%$ had not completed a high school education, and $32 \%$ had limited health literacy. Median Charlson Comorbidity Index score was 7 (interquartile range: 6,8 ). Only $22 \%$ of nephrologists had referred their patients for formal predialysis education at the time of enrollment. Additionally, $23 \%$ of nephrologists responded "No" to the Surprise Question. There was a higher proportion of male participants in the verbal arm (64 vs. 38\%) and a higher proportion of participants who had been referred for standard pre-dialysis education in the video arm (32 vs. 12\%). 
Fig. 2. Factors associated with correct supportive care knowledge. Patients of Asian or other race $(n=3)$ removed from analyses due to cells with no preference for supportive kidney care. Variables: sex, male versus female; race, white versus black; ethnicity, non-Hispanic versus Hispanic; high school, greater than 12 th grade education versus less than 12th grade education; income, income $\leq 30 \mathrm{k}$ versus $>30 \mathrm{k}$; REALM score, Rapid Estimate of Adult Literacy in Medicine score; CCI score, Charlson Comorbidity Index score; Pre-ed referral, have you referred your patient for pre-dialysis education? (yes vs. no); Surprise ques, would you be surprised if your patient died in the next 1 year? (no vs. yes); SKC (supportive kidney care) education, verbal script versus video.

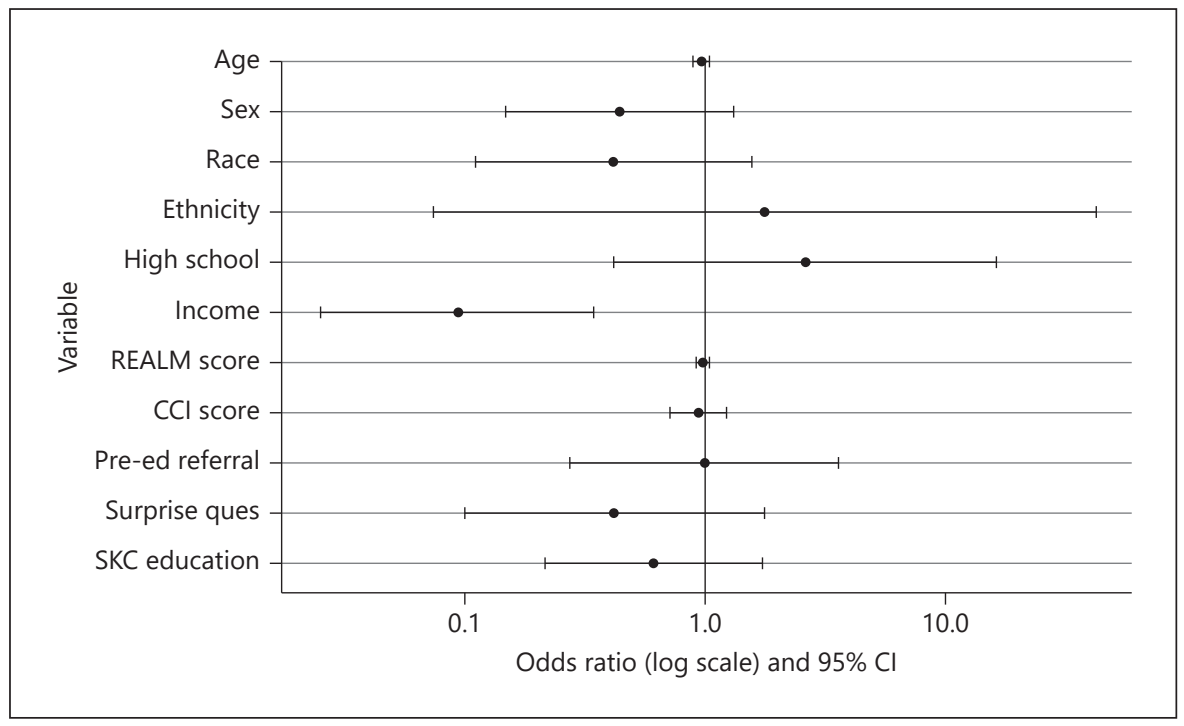

Table 2. Knowledge and preference for supportive kidney care ${ }^{\mathrm{a}, \mathrm{b}}$

$\begin{array}{llll}\text { Total } & \text { Verbal script } & \text { Video } \\ (N=100) & (N=50) & (N=50) & p \text { value }\end{array}$

Pre-education

Mean supportive kidney care knowledge score $( \pm S D)$

Correct knowledge of supportive care, $\%$

Preference for supportive care, \%

$\begin{array}{ll}2.02( \pm 0.96) & 1.94( \pm 1.02) \\ 41 & 38 \\ 21 & 26\end{array}$

$\begin{array}{ll}2.1( \pm 0.91) & 0.41 \\ 44 & 0.68 \\ 16 & 0.33\end{array}$

Post-education

Mean supportive kidney care knowledge score $( \pm S D)$

Correct knowledge of supportive care, $\%$

Preference for supportive care, \%

$\begin{array}{lc}2.36( \pm 0.93) & 2.38( \pm 0.90) \\ 61 & 58 \\ 26 & 30\end{array}$

$\begin{array}{ll}2.34( \pm 0.91) & 0.83 \\ 64 & 0.68 \\ 22 & 0.49\end{array}$

a Post-education knowledge McNemar's test: overall - 13.33, $p<0.01$; verbal $-7.14, p=0.01$; video $-6.25, p=0.01$. ${ }^{\mathrm{b}}$ Post-education preference McNemar's test: overall $-2.27, p=0.13$; verbal $-0.67, p=0.41$; video $-1.80, p=0.18$.

\section{Knowledge of Supportive Kidney Care}

Prior to receiving education, all participants achieved a mean knowledge score of $2.02(\mathrm{SD} \pm 0.96)$ and $41 \%$ of participants had correct knowledge of supportive kidney care at baseline (Table 2). There was no significant difference in baseline knowledge score (mean score, verbal arm vs. video arm: 1.94 [SD \pm 1.02 ] versus 2.1 [SD \pm 0.91 ], $p=0.41$ ), or proportion of those with correct knowledge (verbal arm vs. video arm: 38 vs. $44 \%, p=0.68$; Table 2 ).

After receiving education, mean knowledge scores increased significantly (overall 2.36 [SD \pm 0.93$], p<0.01$ ) although there was no difference in post-education knowledge scores between the study arms (verbal arm vs. video arm: 2.38 [SD \pm 0.90$]$ vs. 2.34 [SD \pm 0.91$], p=0.83$; Table 2). Furthermore, $61 \%$ of participants reported correct knowledge of supportive kidney care (McNemar's statistic $=13.33, p<0.01)$ and the effect of education was similar among participants in the verbal (McNemar's statistic $=7.14, p=0.01)$ and video arms (McNemar's statistic $=$ $6.25, p=0.01$ ). On multivariable analyses, an income of less than 30,000 USD was significantly associated with lower odds of correct knowledge of supportive kidney care (aOR 0.10 [95\% CI, 0.03-0.35]; Fig. 2).

\section{Preference for Supportive Kidney Care}

At baseline, $21 \%$ of participants preferred supportive kidney care if their disease progressed to ESRD. There was no significant difference in preference for supportive kidney care between the 2 study arms (verbal arm vs. video arm: 26 vs. $16 \%, p=0.33$; Table 2 ). 
Fig. 3. Factors associated with preference for supportive kidney care. Patients of Asian or other race $(n=3)$ removed from analyses due to cells with no preference for supportive kidney care. Variables: sex, male versus female; race, white versus black; ethnicity, non-Hispanic versus Hispanic; high school, greater than 12th grade education versus less than 12 th grade education; income, income $\leq 30 \mathrm{k}$ versus $>30 \mathrm{k}$; REALM score, Rapid Estimate of Adult Literacy in Medicine score; CCI score, Charlson Comorbidity Index score; Pre-ed referral, have you referred your patient for predialysis education? (yes vs. no); Surprise ques, would you be surprised if your patient died in the next 1 year? (no vs. yes); SKC (Supportive kidney care) education, verbal script versus video.

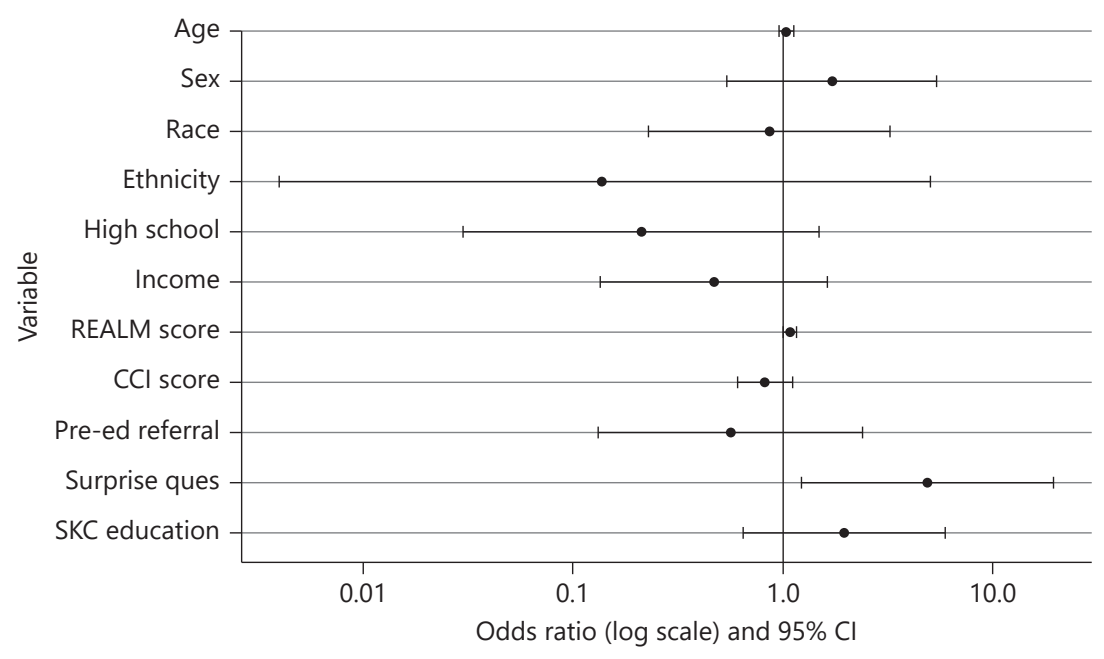

After receiving education, $26 \%$ of participants preferred supportive kidney care; however, this was not significantly different compared to baseline (overall McNemar's statistic $=2.27, p=0.13$; verbal arm McNemar's statistic $=0.67, p=0.41 ;$ video arm McNemar's statistic $=$ $1.80, p=0.18$; Table 2). In addition, there was no difference in the proportion of participants who preferred supportive kidney care between the verbal and video arms $(p=0.49$, Table 2). On multivariable analyses, total health literacy score and nephrologists' answer of "No" to the Surprise Question were significantly associated with higher odds of preference for supportive kidney care treatment (health literacy aOR 1.08 [95\% CI, 1.003-1.17]; Surprise Question aOR 4.87 [95\% CI, 1.23-19.43]; Fig. 3).

\section{Satisfaction and Acceptability}

Of participants who viewed the video, $96 \%$ found it to be helpful, $96 \%$ felt comfortable while watching, $98 \%$ felt satisfied with the content, and 96\% would recommend the video to others (online suppl. Table 2).

\section{Discussion}

Among older participants with advanced CKD, we found knowledge of supportive kidney care increased significantly after receiving verbal and video education. However, we did not detect a significant difference between the two educational arms. Additionally, participants who had lower income were less likely to have correct knowledge of supportive kidney care. Preferences for supportive kidney care did not change post-education due to receiving education; however, health literacy score and nephrologists' answer to the Surprise Question were significantly associated with patient preference for this type of care. Last, among participants who received video education, the majority reported high satisfaction and acceptability ratings.

Our results demonstrate the impact of a supportive kidney care video decision aid on improving knowledge of this treatment among older patients with advanced CKD. Although the clinical relevance of change in knowledge score in this study is unknown, we were reasonably able to demonstrate that enrolled participants had lower baseline knowledge about supportive kidney care. This confirms previous literature that shows routine care for advanced CKD likely does not include adequate information about this treatment. Our results align with published data from a qualitative study of older patients in the UK that showed patients who were managed in nephrology clinics without established supportive kidney care pathways were less likely to have knowledge of this option [11]. In contrast, patients who were managed with supportive kidney care not only had a good understanding of how their livelihood could be affected by dialysis, but also how supportive kidney care was not fixed and courses of future treatment could indeed include dialysis as desired. Given time constraints during clinical encounters, a short supportive kidney care video decision aid may be used before or after visits to improve knowledge and facilitate subsequent care discussions. 
Shared decision-making for ESRD treatments should encompass conversations between clinicians, patients, and caregivers about the risk and benefits of both dialytic and non-dialytic treatments in the context of a patient's goals and values [39]. However, despite long-standing advocacy for supportive kidney care delivery among national and international nephrology organizations, educational tools that inform patients and their loved ones are limited and fewer have established efficacy on objective knowledge [14, 17, 19, 40, 41]. We demonstrated that a supportive kidney video decision aid was well received among our study cohort- which counters historic beliefs among clinicians that speaking about non-dialytic treatments may cause unintended psychological harm toward patients [42]. In this context, patients and their loved ones may feel more empowered to discuss their hopes, worries, and fears with their clinicians and how these may best be integrated into future care plans.

Participants in our study largely endorsed preference for dialytic care if their kidney disease were to progress even after receiving education about supportive kidney care. This finding was not unexpected, given that we did not assess participants' prognostic awareness, which is strongly associated with future preference for care [43]. Although knowledge of treatment options is essential to decision-making, readiness to make decisions and discussion of treatment options with clinicians are also significant factors [25]. Consistent with these notions, we found that physicians' answer to the Surprise Question was strongly associated with participants' preference for supportive kidney care. This may have reflected previous prognostic and goals of care discussions between participants and their clinicians during clinical encounters. Recent studies have shown that the Surprise Question may be useful in helping clinicians identify poor prognoses and functional statuses as well as frailty among older patients with advanced CKD $[38,44,45]$. We also found that higher health literacy was associated with preference for supportive kidney care, which reinforces the importance of clear communication and dialogue between clinicians and patients to better assist them in navigating their health decisions [46]. Health literacy has been associated with advance care planning an important consideration for older patients with advanced CKD [47-49]. Further investigation is warranted to ascertain whether the addition of an educational supportive kidney care video decision aid in clinical practice can influence patient-centered outcomes, including advance care planning and treatment decision-making.

Our study has several limitations. Study coordinators who collected study data were not blinded to randomiza- tion and this may have introduced bias. The cross-sectional nature of this study did not allow longitudinal follow-up to assess participant retention of knowledge or change in preference for care. As our primary outcome was proximal knowledge, we also did not assess other important decision-making outcomes, including decisional conflict and confidence.

Further, we cannot comment on generalizability of results among patients living in different regions, patients of different socioeconomic statuses, younger patients, or patients with different stages of kidney disease, including those receiving dialysis. We also did not ascertain participants' previous conversations about supportive kidney care with clinicians and were unable to control for these in the analyses. Last, there are no validated knowledge surveys about supportive kidney care; therefore, we used a question that was largely developed from literature review and expert opinion. This survey item may have caused a ceiling effect, which resulted in a lack of demonstrated efficacy of the video decision aid.

To the best of our knowledge, this study represents the first pilot randomized trial of a video decision aid on knowledge of supportive kidney care. The landscape of care for older and frail patients with advanced CKD has changed to prioritize shared decision-making, quality of life, and better transitions of care at the end of life [5052]. Our trial demonstrated that knowledge of supportive kidney care improved significantly among participants regardless of the educational intervention - this only enriches shared decision-making. Rigorous development and testing of patient-facing decision aids are crucial to achieving high-quality care for this patient population. Video decision aids offer an innovative and scalable tool to empower patients and families in shared decisionmaking that includes supportive kidney care.

\section{Acknowledgement}

We thank Dr. Ravi Thadhani who provided research coordinator support for this project.

\section{Statement of Ethics}

All participants provided written informed consent. This study was approved by the Institutional Review Boards at Partners HealthCare and the University of Pennsylvania.
Eneanya et al. 


\section{Conflict of Interest Statement}

A.E.V. has a financial interest in the nonprofit foundation Nous Foundation (d/b/a ACP Decisions, 501c3). The nonprofit organization develops advanced care planning video decision aids and support tools. A.E.V. interests were reviewed and are managed by Massachusetts General Hospital and Partners HealthCare in accordance with their conflict of interest policies. All other authors declare that they have no relevant conflicts of interests.

\section{Funding Sources}

N.D.E. was supported by NIH grant K23DK114526. The funder did not have a role in study design, collection, analyses, interpretation of data, writing the report, and the decision to submit the report for publication.

\section{Author Contributions}

Research idea and study design: N.D.E., M.J.G., J.O.S., D.J.R.S., M.K.P.-O., and A.E.V.; data acquisition: N.D.E., S.G.P., and T.L.S.; data analysis/interpretation of data: N.D.E., W.W., M.K.P.-O., and A.E.V.; and supervision or mentorship: M.K.P.-O. and A.E.V. Each author contributed important intellectual content during manuscript drafting or revision, accepts personal accountability for the author's own contributions, and agrees to ensure that questions pertaining to the accuracy or integrity of any portion of the work are appropriately investigated and resolved.

\section{Availability of Data and Material}

De-identified data from this project are available to qualified researchers for approved scientific use immediately following publication for up to 3 years. Data access proposals that are methodologically sound should be directed to the corresponding author.

\section{References}

1 Saran R, Robinson B, Abbott KC, Agodoa LY, Albertus P, Ayanian J, et al. US Renal Data System 2016 Annual Data Report: epidemiology of kidney disease in the United States. Am J Kidney Dis. 2020 Jan;69(3 Suppl 1):A7.

2 Saran R, Li Y, Robinson B, Ayanian J, Balkrishnan R, Bragg-Gresham J, et al. US Renal Data System 2014 Annual Data Report: epidemiology of kidney disease in the United States. Am J Kidney Dis. 2019 Mar;66(1 Suppl 1):Svii-305.

3 Rouveure AC, Bonnefoy M, Laville M. [Conservative treatment, hemodialysis or peritoneal dialysis for elderly patients: The choice of treatment does not influence the survival]. Nephrol Ther. 2016 Feb;12(1):32-7.

4 Verberne WR, Geers AB, Jellema WT, Vincent HH, van Delden JJ, Bos WJ. Comparative survival among older adults with advanced kidney disease managed conservatively versus with dialysis. Clin J Am Soc Nephrol. 2016 Apr 7;11(4):633-40.

5 Raman M, Middleton RJ, Kalra PA, Green D. Outcomes in dialysis versus conservative care for older patients: a prospective cohort analysis of stage 5 chronic kidney disease. PLoS One. 2018;13(10):e0206469.

6 van Loon IN, Goto NA, Boereboom FTJ, Verhaar MC, Bots ML, Hamaker ME. Quality of life after the initiation of dialysis or maximal conservative management in elderly patients: a longitudinal analysis of the Geriatric assessment in OLder patients starting Dialysis (GOLD) study. BMC Nephrol. 2019 Mar 29; 20(1):108.

7 O'Connor NR, Kumar P. Conservative management of end-stage renal disease without dialysis: a systematic review. J Palliat Med. 2012 Feb;15(2):228-35.

8 Wong SPY, Yu MK, Green PK, Liu CF, Hebert PL, O'Hare AM. End-of-life care for patients with advanced kidney disease in the US veter- ans affairs health care system, 2000-2011. Am J Kidney Dis. 2018 Jul;72(1):42-9.

9 Rubio Rubio MV, Lou Arnal LM, Gimeno Orna JA, Munguía Navarro P, Gutiérrez-Dalmau A, Lambán Ibor E, et al. Supervivencia y calidad de vida en pacientes ancianos en tratamiento renal conservador. Nefrología. 2019 Mar-Apr;39(2):141-50.

10 Saeed F, Adams H, Epstein RM. Matters of life and death: why do older patients choose conservative management? Am J Nephrol. 2020; 51(1):35-42.

11 Tonkin-Crine S, Okamoto I, Leydon GM, Murtagh FE, Farrington K, Caskey F, et al. Understanding by older patients of dialysis and conservative management for chronic kidney failure. Am J Kidney Dis. 2015 Mar; 65(3):443-50.

12 Karlin J, Chesla CA, Grubbs V. Dialysis or death: a qualitative study of older patients' and their families' understanding of kidney failure treatment options in a US public hospital setting. Kidney Med. 2019;1(3):124-30.

13 Selman LE, Bristowe K, Higginson IJ, Murtagh FEM. The views and experiences of older people with conservatively managed renal failure: a qualitative study of communication, information and decision-making. BMC Nephrol. 2019 Feb 4;20(1):38.

14 Fortnum D, Grennan K, Smolonogov T. Endstage kidney disease patient evaluation of the Australian "My Kidneys, My Choice" decision aid. Clin Kidney J. 2015 Aug;8(4):46975.

15 Isnard Bagnis C, Crepaldi C, Dean J, Goovaerts T, Melander S, Nilsson EL, et al. Quality standards for predialysis education: results from a consensus conference. Nephrol Dial Transplant. 2015 Jul;30(7):1058-66.

16 Roderick P, Rayner H, Tonkin-Crine S, Okamoto I, Eyles C, Leydon G, et al. A national study of practice patterns in UK renal units in the use of dialysis and conservative kidney management to treat people aged 75 years and over with chronic kidney failure. Health Services and Delivery Research. Southampton (UK): NIHR Journals Library; 2015.

17 Winterbottom AE, Gavaruzzi T, Mooney A, Wilkie M, Davies SJ, Crane D, et al. Patient acceptability of the Yorkshire Dialysis Decision Aid (YoDDA) booklet: a prospective non-randomized comparison study across 6 predialysis services. Perit Dial Int. 2016 JulAug;36(4):374-81.

18 Davis JL, Davison SN. Hard choices, better outcomes: a review of shared decision-making and patient decision aids around dialysis initiation and conservative kidney management. Curr Opin Nephrol Hypertens. 2017 May;26(3):205-13.

19 Subramanian L, Zhao J, Zee J, Knaus M, Fagerlin A, Perry E, et al. Use of a decision aid for patients considering peritoneal dialysis and in-center hemodialysis: a randomized controlled trial. Am J Kidney Dis. 2019 Sep; 74(3):351-60.

20 Stacey D, Bennett CL, Barry MJ, Col NF, Eden KB, Holmes-Rovner M, et al. Decision aids for people facing health treatment or screening decisions. Cochrane Database Syst Rev. 2014;1(10):Cd001431.

21 El-Jawahri A, Mitchell SL, Paasche-Orlow MK, Temel JS, Jackson VA, Rutledge RR, et al. A randomized controlled trial of a CPR and intubation video decision support tool for hospitalized patients. J Gen Intern Med. 2015 Aug;30(8):1071-80.

22 Mitchell SL, Shaffer ML, Cohen S, Hanson LC, Habtemariam D, Volandes AE. An advance care planning video decision support tool for nursing home residents with advanced dementia: a cluster randomized clinical trial. JAMA Intern Med. 2018 Jul 1;178(7): 961-9. 
23 Waterman AD, Peipert JD, McSorley A-M, Goalby CJ, Beaumont JL, Peace L. Direct delivery of kidney transplant education to black and low-income patients receiving dialysis: a randomized controlled trial. Am J Kidney Dis. 2019 Nov;74(5):640-9.

24 Norman GR, Sloan JA, Wyrwich KW. Interpretation of changes in health-related quality of life: the remarkable universality of half a standard deviation. Med Care. 2003 May; 41(5):582-92.

25 Prakash S, McGrail A, Lewis SA, Schold J, Lawless ME, Sehgal AR, et al. Behavioral stage of change and dialysis decision-making. Clin J Am Soc Nephrol. 2015 Feb 6;10(2):197-204.

26 Schulz KF, Altman DG, Moher D. CONSORT 2010 statement: updated guidelines for reporting parallel group randomised trials. PLoS Med. 2010 Mar 23;7(3):e1000251.

27 Levey AS, Stevens LA, Schmid CH, Zhang YL, Castro AF 3rd, Feldman HI, et al. A new equation to estimate glomerular filtration rate. Ann Intern Med. 2009 May 5;150(9):604-12.

28 Levey AS, Bosch JP, Lewis JB, Greene T, Rogers N, Roth D. A more accurate method to estimate glomerular filtration rate from serum creatinine: a new prediction equation. Modification of Diet in Renal Disease Study Group. Ann Intern Med. 1999;130(6):461470. 10.7326/0003-4819-130-6-19990316000002. 10075613

29 Pfeiffer E. A short portable mental status questionnaire for the assessment of organic brain deficit in elderly patients. J Am Geriatr Soc. 1975 Oct;23(10):433-41.

30 Grant BKSJ. Documenting the documentary: close readings of documentary film and video. Detroit (MI): Wayne Stage University Press; 1998.

31 Volandes AE, Barry MJ, Wood F, Elwyn G. Audio-video decision support for patients: the documentary genré as a basis for decision aids. Health Expect. 2013 Sep;16(3):e80-8.

32 Epstein AS, Volandes AE, Chen LY, Gary KA, Li Y, Agre P, et al. A randomized controlled trial of a cardiopulmonary resuscitation video in advance care planning for progressive pancreas and hepatobiliary cancer patients. J Palliat Med. 2013 Jun;16(6):623-31.

33 Davis TC, Long SW, Jackson RH, Mayeaux EJ, George RB, Murphy PW, et al. Rapid estimate of adult literacy in medicine: a short- ened screening instrument. Fam Med. 1993 Jun;25(6):391-5.

34 Cavanaugh KL, Wingard RL, Hakim RM, Eden S, Shintani A, Wallston KA, et al. Low health literacy associates with increased mortality in ESRD. J Am Soc Nephrol. 2010 Nov; 21(11):1979-85.

35 Wright JA, Wallston KA, Elasy TA, Ikizler TA, Cavanaugh KL. Development and results of a kidney disease knowledge survey given to patients with CKD. Am J Kidney Dis. 2011 Mar;57(3):387-95.

36 Cavanaugh KL, Osborn CY, Tentori F, Rothman RL, Ikizler TA, Wallston KA. Performance of a brief survey to assess health literacy in patients receiving hemodialysis. Clin Kidney J. 2015 Aug;8(4):462-8.

37 Charlson ME, Pompei P, Ales KL, MacKenzie CR. A new method of classifying prognostic comorbidity in longitudinal studies: development and validation. J Chronic Dis. 1987; 40(5):373-83.

38 Baddour NA, Robinson-Cohen C, Lipworth L, Bian A, Stewart TG, Jhamb M, et al. The surprise question and self-rated health are useful screens for frailty and disability in older adults with chronic kidney disease. J Palliat Med. 2019 Dec;22(12):1522-9.

$39 \mathrm{Li} \mathrm{KC}$, Brown MA. Consenting for dialysis or its alternative: systematic process is needed. Clin J Am Soc Nephrol. 2020 Feb 4;15(4): 560-2.

40 Moss AH. Revised dialysis clinical practice guideline promotes more informed decisionmaking. Clin J Am Soc Nephrol. 2010 Dec; 5(12):2380-3.

41 Davison SN, Levin A, Moss AH, Jha V, Brown EA, Brennan F, et al. Executive summary of the KDIGO Controversies Conference on Supportive Care in Chronic Kidney Disease: developing a roadmap to improving quality care. Kidney Int. 2015 Sep;88(3): 447-59.

42 Ladin K, Pandya R, Kannam A, Loke R, Oskoui T, Perrone RD, et al. Discussing conservative management with older patients with CKD: an interview study of nephrologists. Am J Kidney Dis. 2018 May;71(5):627-35.

43 Wachterman MW, Marcantonio ER, Davis RB, Cohen RA, Waikar SS, Phillips RS, et al. Relationship between the prognostic expectations of seriously ill patients undergoing he- modialysis and their nephrologists. JAMA Intern Med. 2013 Jul 8;173(13):1206-14.

44 Salat H, Javier A, Siew ED, Figueroa R, Lipworth L, Kabagambe E, et al. Nephrology provider prognostic perceptions and care delivered to older adults with advanced kidney disease. Clin J Am Soc Nephrol. 2017 Nov 7; 12(11):1762-70.

45 Schmidt RJ, Landry DL, Cohen L, Moss AH, Dalton C, Nathanson BH, et al. Derivation and validation of a prognostic model to predict mortality in patients with advanced chronic kidney disease. Nephrol Dial Transplant. 2019 Sep 1;34(9):1517-25.

46 Cassidy BP, Harwood L, Getchell LE, Smith M, Sibbald SL, Moist LM. Educational support around dialysis modality decision making in patients with chronic kidney disease: qualitative study. Can J Kidney Health Dis. 2018;5:2054358118803323.

47 Waite KR, Federman AD, McCarthy DM, Sudore R, Curtis LM, Baker DW, et al. Literacy and race as risk factors for low rates of advance directives in older adults. J Am Geriatr Soc. 2013 Mar;61(3):403-6.

48 Ladin K, Buttafarro K, Hahn E, Koch-Weser S, Weiner DE. "End-of-Life Care? I'm not Going to Worry About That Yet." Health literacy gaps and end-of-life planning among elderly dialysis patients. Gerontologist. 2018 Mar 19; 58(2):290-9.

49 Nouri SS, Barnes DE, Volow AM, McMahan $\mathrm{RD}$, Kushel M, Jin C, et al. Health literacy matters more than experience for advance care planning knowledge among older adults. J Am Geriatr Soc. 2019 Oct;67(10):2151-6.

50 O'Hare AM, Richards C, Szarka J, McFarland LV, Showalter W, Vig EK, et al. Emotional impact of illness and care on patients with advanced kidney disease. Clin J Am Soc Nephrol. 2018 Jul 6;13(7):1022-9.

51 Wong SPY, McFarland LV, Liu CF, Laundry RJ, Hebert PL, O'Hare AM. Care practices for patients with advanced kidney disease who forgo maintenance dialysis. JAMA Intern Med. 2019 Jan 22;179(3):305.

52 Wong SPY, Boyapati S, Engelberg RA, Thorsteinsdottir B, Taylor JS, O'Hare AM. Experiences of US nephrologists in the delivery of conservative care to patients with advanced kidney disease: a national qualitative study. Am J Kidney Dis. 2020 Feb;75(2):167-76. 